\title{
LER E ESCREVER NA EDUCAÇÃO INFANTIL: A PARTICIPAÇÃO DAS VOZES E DOS CORPOS NA CONSTRUÇÃO DESTAS LINGUAGENS
}

\section{LECTURA Y ESCRITURA EN LA EDUCACIÓN INFANTIL: LA PARTICIPACIÓN DE VOCES Y ÓRGANOS EN LA CONSTRUCCIÓN DE ESTAS LENGUAS}

https://orcid.org/0000-0002-9619-5329 Debora da Silva Cruz Conceição Cristina ${ }^{\text {A }}$

${ }^{\text {A }}$ Universidade Federal do Rio de Janeiro (UFRJ), Rio de Janeiro, RJ, Brasil

Recebido em: 14 out. 2020 | Aceito em: 08 jun. 2021 Correspondência: Debora Cristina debora.cristina.professora@gmail.com

\begin{abstract}
Resumo
Este relato de experiências traz um recorte de propostas vividas no ano de 2019 em uma turma de Educação Infantil com faixa etária entre 5 e 6 anos (Pré-Escola II ${ }^{\mathrm{i}}$ ), na rede municipal do Rio de Janeiro, em um EDI ii, localizado na Zona Norte, entre as comunidades Jacarezinho e Manguinhos. As narrativas apresentadas aqui como estratégia metodológica mostram que, assim como com outras linguagens, a leitura e a escrita podem ser experimentadas em práticas cotidianas, não ficando restritas ao uso do papel. Portanto, a/o professor ${ }^{\text {iii }}$ a/or com olhar e escuta sensíveis às expressões das crianças pode proporcionar experiências significativas para elas.
\end{abstract}

Palavras-chave: Crianças; Protagonismo; Criação; Leitura; Escrita.

\section{Resumen}

Este informe de experiencias presenta una selección de propuestas vividas en el año 2019 en un grupo de Educación Infantil con edades entre 5 y 6 años (Preescolar II), en la red municipal de Río de Janeiro, en un EDI, ubicado en la Zona Norte, entre las comunidades Jacarezinho y Manguinhos. Las narrativas que aquí se presentan como estrategia metodológica, muestran que, al igual que con outros lenguages, la lectura y la escritura se pueden experimentar en la práctica cotidiana, no restringiéndose al uso del papel. Por lo tanto, el maestro con ojos sensibles y escuchando las expresiones de los niños puede brindarles experiencias significativas.

Palabras clave: Niños; Protagonismo; Creación; Lectura; Escritura.

\section{Registrar, Repensar, Compartilhar}

As cenas que serão apresentadas neste relato, aconteceram em um EDI na Zona Norte do Rio de Janeiro, numa região periférica. Esta unidade, atende crianças de 3 a 6 anos, com um total de 8 turmas. Atuo neste Espaço de Desenvolvimento Infantil desde 2016 em turmas de pré-escola I e II e especialmente para este relato, tratarei de uma turma de que fui professora nos anos de 2018 e 2019, porém as situações trazidas aqui são do ano de 2019, num grupo de 28 crianças. 
Como professora desse grupo, percebi o interesse das crianças pela escrita por meio da observação, da escuta, das brincadeiras e nas produções diversas que elas criavam diariamente. Por conta disso, entendo que ao fazer o registro dos relatos de uma prática, a/o professora/or revisita as atividades e estratégias já experimentadas com suas turmas e tem a possibilidade de repensar ou recriar novas propostas com novos objetivos ou com objetivos mais específicos, pois "[...] é na relação entre teoria e a prática que estão as oportunidades de mudança e crescimento da qualidade que almejamos." (AMARAL, 2007 p. 15)

Portanto, até mesmo ao fazer os registros, a memória da professora já está carregada de sentidos, de novas ideias, de observações, o que colabora para uma construção da rotina que conta com a participação das crianças, das famílias, e que explora as possibilidades criadas pelo próprio cotidiano. Nesse sentido, a valorização do que ocorre já pode ser considerada como aprendizagem, mesmo que não tenha surgido de uma proposta trazida pela professora. Muitas são as situações de aprendizado, troca e criação.

Segundo o Referencial Curricular Nacional para a Educação Infantil (1998), na faixa etária entre 4 e 6 anos, as crianças passam a se interessar pela representação escrita do nome. Por conta deste e de outros documentos que também orientam sobre o trabalho com a escrita na Educação Infantil, existem algumas propostas que podem ser incorporadas às rotinas das crianças pequenas, como por exemplo, identificar seus pertences com o nome.

Com o objetivo de compartilhar minha prática, reforçando que ela possui embasamento teórico e que dialoga com o documento: Diretrizes Curriculares Nacionais (2013) e com autores como Corsino (2009), Ferreiro (2000) e Morais (2012), entre outros, ao passo que reafirmo sobre a importância da professora fazer registros das vivências com as crianças, com relação à diferentes áreas, mas aqui aponto em especial as propostas com leitura e escrita. Apresento então algumas das muitas possibilidades de vivências com essas linguagens em situações diversas surgidas com esse grupo, na escola. A partir de diferentes movimentos e momentos entre mim e o grupo, os registros se ampliaram, dando origem a este trabalho.

Com os registros em mãos, é possível fazer uso deles para pensar novas propostas considerando os interesses do grupo. Dessa forma é possível repensar, analisar e até mesmo repetir ou transformar propostas já vivenciadas.

Compartilhar essas propostas também é fundamental, pois além de dar visibilidade ao trabalho com a escrita na Educação Infantil, mostra que é possível aliar teoria e prática para trazer uma leitura e escrita com significado para as crianças pequenas. 


\section{Mas as palavras servem para...? Considerando os saberes das crianças}

Registrar a rotina diariamente, escrever um bilhete para a turma ao lado, ler o cardápio na hora do almoço, registrar regras de convívio dentro do espaço escolar, criar histórias coletivamente, registrar uma música ou anotar a receita de um bolo que fizemos juntos, são algumas das possibilidades de mostrar para as crianças que tudo o que falamos pode ser escrito. Ou seja, esse registro pode estar presente em diferentes situações. Fazer essas e outras ações com frequência, no grupo, colaboram para que o interesse e a curiosidade das crianças pelo mundo letrado seja cada vez mais aguçada. Dessa forma, é possível que elas, aos poucos, percebam as marcas que a escrita pode nos trazer e comunicar, e percebam suas funcionalidades.

Mesmo que a escola precise cumprir suas funções pedagógicas dentre elas, precisa estar o respeito às origens das crianças, sua diversidade e valorização dos conhecimentos, vistos como forma de ampliação do diálogo e maior possibilidade de trocas e aprendizados entre os diferentes pares. As palavras deveriam servir para que pudéssemos nos comunicar e dialogar, buscando construir e ressignificar. Porém, o que ainda muito se vê é que:

[...] despreza-se o modo de fala das crianças de grupos socialmente marginalizados como inconveniente para dar acesso à escrita. É preciso enfatizar que o preconceito linguístico é um dos mecanismos de discriminação, no interior da escola, com maiores consequências para a criança. Primeiro, porque ao desprezar a variante dialetal se está desprezando não somente a criança, mas também o grupo social a que ela pertence [...] (FERRERO, 2000, p. 26)

Por isso, é importante que a escola desde cedo aceite e valorize as variantes não só na língua, mas nas diferentes formas de se expressar apresentadas pelas crianças e suas famílias. Isso certamente poderá colaborar para que as aprendizagens como um todo façam parte das rotinas e para que as crianças possam sentir-se dentro desses processos de produção escrita. $\mathrm{Ou}$ seja, considerando os saberes que as crianças já possuem e não julgando apenas o saber produzido pela escola, como aquele de maior valor.

Já na Educação Infantil, atividades que colocam as crianças como autoras das propostas e que valorizam suas vozes e seus pensamentos, podem encorajar futuros leitores e escritores que entendem a escrita como uma linguagem com muita relevância em nossa sociedade, e isso deve continuar a ser estimulado ao longo da vida escolar.

É importante que, nessa fase, da Educação Infantil, as crianças possam escutar e serem ouvidas, expressando seus desejos e ideias, possam conversar, contar e recontar situações ou histórias, dar recados, cantar, dramatizar, falar sobre seus interesses ou dúvidas, colaborar com sugestões para a organização do ambiente da sala ou da rotina. Tudo isso pode ser explorado tanto por meio da oralidade, da dramatização, ou até por meio do desenho ou do registro escrito 
pela professora ou pela criança, na forma como ela compreender. Ouvir as crianças, muitas vezes é o melhor caminho para se apresentar menos respostas e se colocar também no lugar de quem continua aprendendo.

Todas essas situações vivenciadas desde a infância, oportunizam, e aproximam as crianças da escrita, mas sem o objetivo de promoção para o Ensino Fundamental, que inclusive não está previsto pelos documentos orientadores da Educação Infantil e sim, com objetivos de conhecer e explorar situações de leitura e escrita, bem como nos aponta Corsino (2009, p. 50) quando nos traz algumas possibilidades de experiências com as palavras na Educação Infantil: "As palavras servem para brincar, para rir, para chorar, para expressar sentimentos e desejos, para convencer, para ordenar, para informar, para aprender, ensinar, para se comunicar, para se comunicar como o outro, para pensar." Ou seja, da mesma forma que as linguagens oral e gráfica vão sendo aos poucos adquiridas conforme as crianças são envolvidas em situações que fazem usos delas, também acontece com a linguagem escrita, pois a professora enquanto leitora e escritora, oferece situações em que as crianças podem perceber que a linguagem escrita comunica, que tem sentido, que transmite uma ideia.

\section{Registrando... (Re)Visitando memórias e histórias de práticas, no aprendizado cotidiano da leitura e da escrita}

A partir de agora, serão apresentados esses recortes, que são uma pequena amostra de situações em que as crianças puderam se colocar como leitoras e escritoras e perceberem os usos da leitura e da escrita em situações reais dentro do grupo. As situações a seguir trazem o protagonismo infantil, a participações das famílias, os pensamentos das crianças sobre a leitura e escrita sem o peso da cobrança de precisar apresentar um resultado do que já sabe à professora, mas tendo a oportunidade de demonstrar todos os seus diversos conhecimentos em diferentes contextos.

Nas propostas que seguem, a leitura e a escrita não se apresentam nas folhinhas com cópias de nomes e sílabas, mas nas brincadeiras, nas contações de história, nos desenhos das crianças, em seus corpos, em suas vozes...

Como exemplos de atividades com linguagem escrita, trago algumas produções de textos coletivos que podem ser feitos com a presença e a contribuição do grupo para registrar um acontecimento do dia, para contar sobre o que sentiram, sobre a sobremesa que prepararam na escola. Esses textos devem ser lidos para a turma e ilustrados pelas crianças. Outro exemplo, seria, ler antes das crianças guardarem, um bilhete que precisa ser enviado às famílias. 
Em todas essas propostas, está impregnada a produção de sentido dada pela criança. Atualmente, sabemos que essa é uma condição necessária para a aprendizagem, bem como sugere Lerner (2002), mas ainda pouco explorada por alguns professores, pois é vista como uma certa "perda de controle", do grupo. O que seria uma ilusão, uma vez que não há como controlar as aprendizagens.

Ainda existe a falsa crença de que a criança precisa ler e escrever exatamente o que espera a professora, orienta, da forma como ela deseja e muitas das vezes, esse registro, não passa por situações reais, mas sim por situações de cópia, ou repetição de um modelo. É importante considerar todas as linguagens que as crianças apresentam, e por meio delas explorar as inúmeras possibilidades que muitas vezes as próprias crianças nos apresentam de brincar com as palavras.

Observando as crianças da turma onde atuava em 2019, percebia que elas também se colocavam no lugar de produtores de texto, de escritores, quando escreviam espontaneamente em seus desenhos, quando escreviam com giz no chão, quando juntos, registrávamos um acontecimento do dia na turma (texto coletivo, onde eu era a escriba), anotávamos os nomes dos presentes e dos faltosos (algumas vezes convidada as crianças para escreverem no quadro os nomes dos amigos que haviam faltado naquele dia), quando escrevíamos um bilhete convidando uma outra turma para brincar com elas, registrávamos uma receita para que pudessem consultar posteriormente e conversávamos sobre seus ingredientes, ou quando brincávamos no chamado: Canto do Escritoriv.

É necessário que as crianças participem de situações de práticas de leitura e escrita e passem a fazer uso dessa escrita como mais uma linguagem para se expressar. Estando em contato com as diferentes linguagens, elas vão se apropriando de seus usos, criando e recriando por meio delas.

Atividades como estas eram cotidianas com esse grupo de crianças, onde atuei por dois anos, o que ampliava suas possibilidades de experimentar a leitura e a escrita em diferentes momentos e estimulava o desejo das crianças de também escreverem da sua maneira. Essas vivências eram feitas sem o objetivo de promover as crianças, mas sim de oportunizar e aproximar esse contato com a leitura e escrita no final da Educação Infantil, a partir do conhecimento que tiveram a oportunidade de elaborar anteriormente, uma vez que

O casamento de práticas de leitura e produção de textos com práticas de reflexão sobre palavras, que temos defendido para se consolidar já na Educação Infantil [...] sabemos que, antes mesmo de terem se apropriado do sistema alfabético, se as crianças tem a oportunidade de participar de práticas de leitura e 
de produção de textos, aprendem uma série de características dos gêneros textuais escritos [...] (MORAIS, 2012, p. 118-119)

Para ilustrar o que indica Morais em seu texto, trago uma produção de um texto coletivo construído por essa mesma turma, com base no projeto desenvolvido pela escola em 2019.

O Projeto Político Pedagógico Anual (PPPA) da instituição foi sobre as regiões brasileiras. Na unidade onde trabalho, o projeto é pensado pelos adultos e divido em bimestres, também pelos adultos. Alguns dos assuntos a serem tratados, também são pensados previamente, o que me inquieta e por conta disso, procuro ouvir ao máximo as contribuições das crianças para que se coloquem como participantes nas construções e nas aprendizagens e tragam sempre as suas questões.

Foram colocadas para as crianças perguntas sobre como poderíamos fazer para conhecer o nosso país, se poderíamos viajar e quais os meios de transporte utilizar. As crianças disseram que para viajar para lugares distantes, seria necessário utilizar um avião e por conta disso, uma criança da turma ensinou aos demais colegas como confeccionar aviões de papel para brincar e embarcar nessa "viagem".

No dia seguinte à confecção dos aviões, registramos a atividade através de um texto coletivo.

AVENTURA DE AVIÃO

Nesse dia, o T. ${ }^{v}$ ensinou para a gente como fazer avião de papel.

Quem não conseguiu fazer, o T. e as crianças ajudaram.

Depois a gente foi lá pra fora e "embarcou” no nosso avião para Minas Gerais.

Foi divertido!

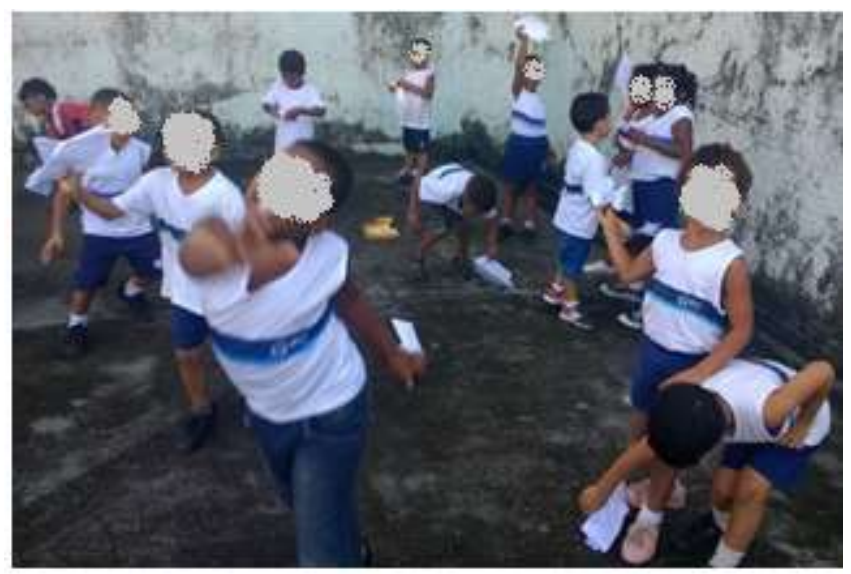

Figura 1: arquivo pessoal 
O aprendizado, também nessa proposta de confecção dos aviões que foi trazida por uma das crianças do grupo, passou pela oralidade, pelo mundo das ideias, pelas artes, pelos corpos, pelo vento, pelos conhecimentos trazidos pelas crianças buscando resolver a questão de uma viagem. O material necessário, o momento em que seriam feitos os aviões, e a forma como iríamos nos organizar, foi combinada com as crianças e registrada por escrito em uma lista, mas, a escrita já estava presente mesmo antes do registro pelas mãos da professora ou das crianças.

Outras atividades foram planejadas dentro desse projeto. Pensando em contemplar a participação das famílias, o que é garantido nas Diretrizes Curriculares Nacionais para a Educação Infantil (DCNEI, 2009), e buscando estreitar laços com essas, construindo uma relação de parceria, convidamos a mãe de uma das crianças da turma que havia viajado para Minas Gerais para apresentar fotos da viagem e conversar com as crianças. Como preparação para a visita, registramos por escrito algumas perguntas que gostaríamos de fazer neste dia.

“- A gente tem que perguntar 10 coisas para a E., mãe da N., porque aí a gente vai ficar sabendo tudo de Minas Gerais!"

“- Então, tem que anotar, porque senão a gente vai esquecer!”

Depois dessa conversa, a turma quis fazer um "piquenique mineiro". Juntos, preparamos um bilhete para as famílias e listamos opções da culinária de Minas Gerais para que as crianças pudessem levar para o lanche coletivo. Diante do que parecia ser apenas uma visita, uma conversa, muitas possibilidades de leitura e escrita foram aparecendo nas sugestões das crianças.

Figura 2 - Lanche coletivo

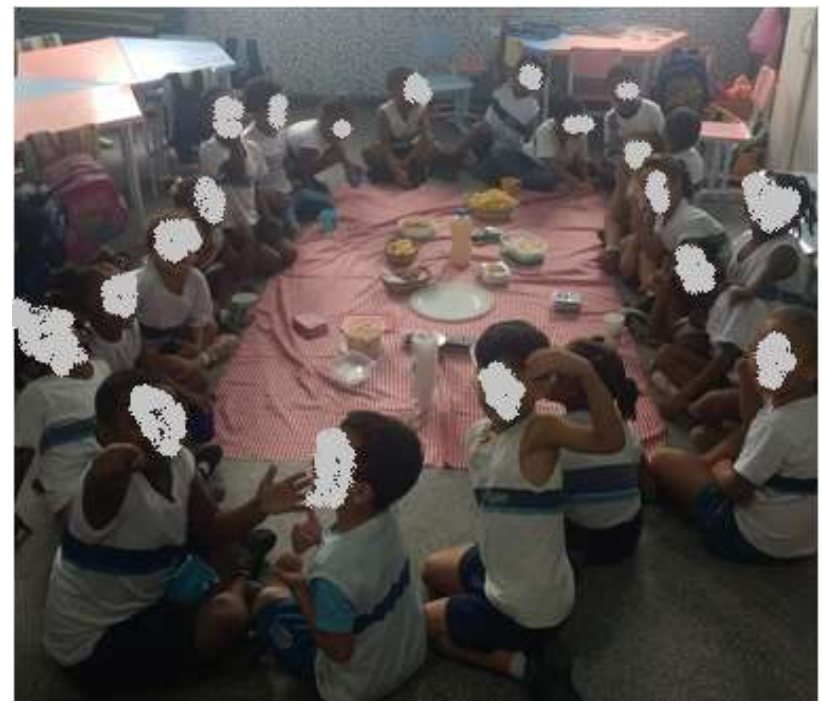

Fonte: Arquivo pessoal 
Desde as perguntas para a entrevista, o registro das respostas, a escrita do texto coletivo sobre o que aprenderam, os desenhos individuais para registrar as aprendizagens, a lista das comidas mineiras e a produção do bilhete para as famílias, em diferentes situações reais e com significado, as crianças exercitavam diariamente a leitura e a escrita dentro de suas rotinas.

Tais situações podem demonstrar também que, lendo para as crianças, acolhendo o que interpretam, fazendo perguntas, a professora as coloca também na situação de leitoras. Assim, como sugerem Guedes e Barreiros (2011, p. 62), as crianças começam a entender que "a escrita é construída de dimensões que vão muito além da representação gráfica por meio de letras". A leitura e a escrita fazem, portanto, parte da vida, parte da nossa cultura e estão presentes e vivas na Educação Infantil, uma vez que a professora propicie situações em que as crianças possam se colocar como leitoras e escritoras.

\section{E o que mais, ensinam as crianças?}

Mais adiante no projeto, seguimos para a Região Norte. Na época, - bem como vemos as cenas se repetirem em 2020 -, as notícias que tínhamos por meio da televisão sobre a Região Amazônica, eram de derrubada de árvores e algumas queimadas, o que sensibilizava bastante algumas crianças do grupo, que traziam vários comentários sobre o assunto em nossas rodas de conversas.

Dentre conversas, documentários, confecção de artesanatos, livros sobre povos indígenas, e depois de assistirem ao desenho "Brasil animado, parte 8- Amazônia ${ }^{\mathrm{v} \text { "” }}$ que mistura imagens reais da floresta com animação, surgiu na turma um maior interesse pelo interior dessa floresta.

Dentro desse contexto de projeto pré-determinado, poucas são as possibilidades de reinvenções, o que nos coloca em um lugar mais de cumprir metas, deixando pouco espaço para experimentar, viver e nos deixar tocar pelas experiências, ao contrário do sentido de experiência trazido por Larrosa (2002). Porém, estar atenta e manter uma escuta sensível às crianças, fez com que a participação delas acontecesse em todos os momentos e as construções de conhecimento, de rotina ou os assuntos de pesquisa, viessem da relação das crianças com o mundo real.

Sendo o interesse das crianças naquele momento por conhecer mais sobre o interior da Floresta Amazônica, conhecer seus elementos e passear por ela, pensei em como proporcionar essa vivência em nossa Unidade. Uma vez que não há espaço verde e os poucos elementos naturais são pássaros e borboletas, criei, no pátio da escola, uma experimentação com água, argila, pedras, areia e folhas secas (contribuição das crianças), dentro de bacias. 
A proposta era de que as crianças pudessem, ao som de uma música instrumental que recriava sons de floresta e com ajuda da minha narração, usar os pés para caminhar por aqueles elementos, imaginando quais caminhos poderiam fazer no centro da Floresta Amazônica e as sensações que seriam possíveis experienciar através deles. Essa experimentação ainda que no coletivo, traz sensações singulares, ressignificando os conhecimentos em construção.

Isso ocorre, pois “[...] posto que não se pode antecipar o resultado, a experiência não é o caminho até um objetivo previsto, até uma meta que se conhece de antemão, mas é uma abertura para o desconhecido, para o que não se pode antecipar nem prever, nem predizer" (LARROSA, 2002, p.19).

Figuras 3 e 4 - Experimentação
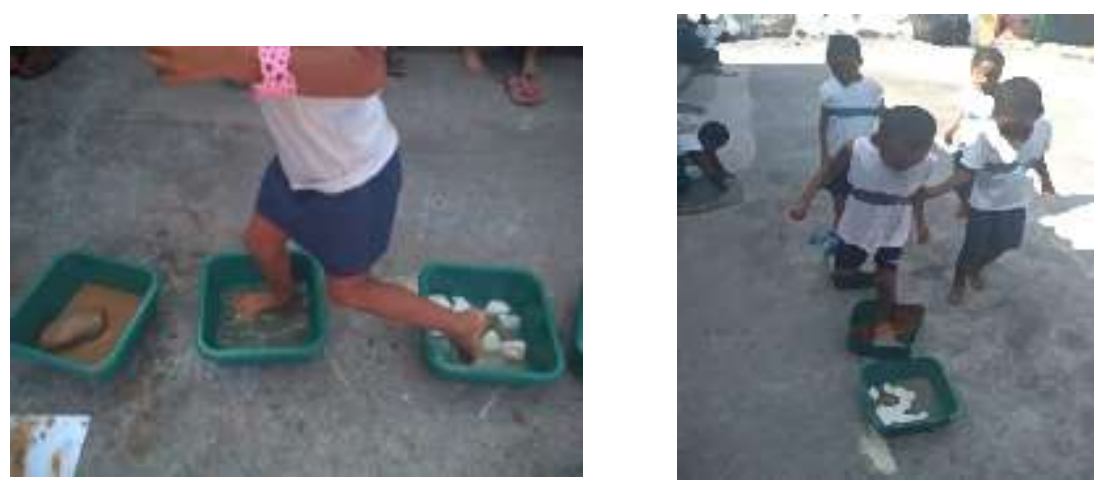

Fonte: Arquivo pessoal.

Nesse caso, não foi preciso escrever, registrar, anotar... a alegria presente nas expressões das crianças era percebida por quem passava, seus olhares, as disputas para repetir a experiência mais uma e mais outra vez... tudo o que vimos nas telas, nos livros, nas histórias, ganhava vida naquela manhã, que só acabou quando uma voz anunciava que já estávamos atrasados para o almoço!

Muitos olhares curiosos dos adultos não entendiam o que acontecia ali. Outros questionavam o porquê de fazer algo que deu tanto trabalho, ou que iria "sujar" o chão todo... Assim como as crianças, em resposta, eu apenas sorria! Imitava aqueles que me ensinavam sobre calma, sobre leveza, sobre alegria, sobre alvoroço. A experiência sentida por cada um, jamais poderia ser registrada por qualquer professora que assim desejasse fazer, pois ela só pode ser contada, mas não descrita. Ler nos corpos, nos olhos também é possível e acredito que eu e as crianças fizemos isso nesta e em outras manhãs. 
As crianças trouxeram a leitura e a escrita em diferentes momentos, por meio de diversas sensações que me fizeram pensar se era isso que Freire queria dizer com: "a leitura do mundo precede a leitura da palavra [...]" $(1989$, p. 9)

\section{Mas nem tudo é projeto, pode ser só... BRINCADEIRA (APRENDIZADO)?!...}

Diante de tanta potência apresentada a mim como professora, pensar em percursos para esse grupo desejoso de ler histórias, escrever adivinhas, de sentir o ar, de viver, de brincar, de explorar, não era fácil. Por isso, voltei a observar o que as crianças vinham fazendo para planejar novos desafios para elas e para mim. Dentre muitas das atividades vivenciadas com essa turma, com relação à leitura e a escrita, algumas das que me chamaram bastante a atenção, se relaciona com o Canto do Escritor, descrito anteriormente. Nessa proposta, as crianças podiam escrever livremente fazendo uso de seus conhecimentos letrados, demostrando também compreender os usos sociais da escrita. A partir dos materiais oferecidos, como guias médicos, blocos de lojas com linhas, ou até cadernos, por exemplo, as crianças imitavam a realidade criando situações em que a leitura e a escrita pudessem estar presentes.

Em alguns momentos, duas crianças se colocavam como professoras e diretoras da escola e davam comandos às demais crianças para escreverem em seus cadernos, ou imitavam situações já ocorridas de atividades ligadas ao projeto, pedindo que escrevessem "do seu jeito" (conforme era dito por mim), palavras sobre o que aprenderam. Outras vezes, faziam listas de nomes de colegas para organizarem, por exemplo, uma "festa de aniversário".

A cena descrita a seguir, ocorreu em um desses momentos de escrita livre no Canto do Escritor e mostra os conhecimentos de duas crianças sobre a visita à um consultório médico e as situações de escrita presentes nesse atendimento.

T. "Fala seu nome para eu escrever aqui. Vai, fala P. que eu vou escrever.

Assim que acabou de falar, T. escrevia o nome do colega de memória em um caderno vertical, de capa dura, cheio de linhas, que fazia parte desse canto.

T. "Agora fala quantos anos você tem para eu poder anotar. Vai fala 5!"

O colega respondeu " 5 ", em seguida, enquanto T. registava o número na linha abaixo do nome do colega nesse mesmo caderno.

P. "Eu vim aqui porque tô doente."

T. "Olha, eu vou escrever nesse papel aqui, o nome do remédio que você vai comprar e a data para você voltar aqui tá bom? Olha vai ser dia 7/6/2019e depois, 8/9/2019?' Deixa só eu assinar aqui. Pronto!" 
A criança, que se passava por médico, escreveu uma data diferente em cada lado do papel. Em seguida, T. entrega um outro papel para P., que agradece e continuam a brincadeira.

Figuras 5 e 6 - Alguns registros
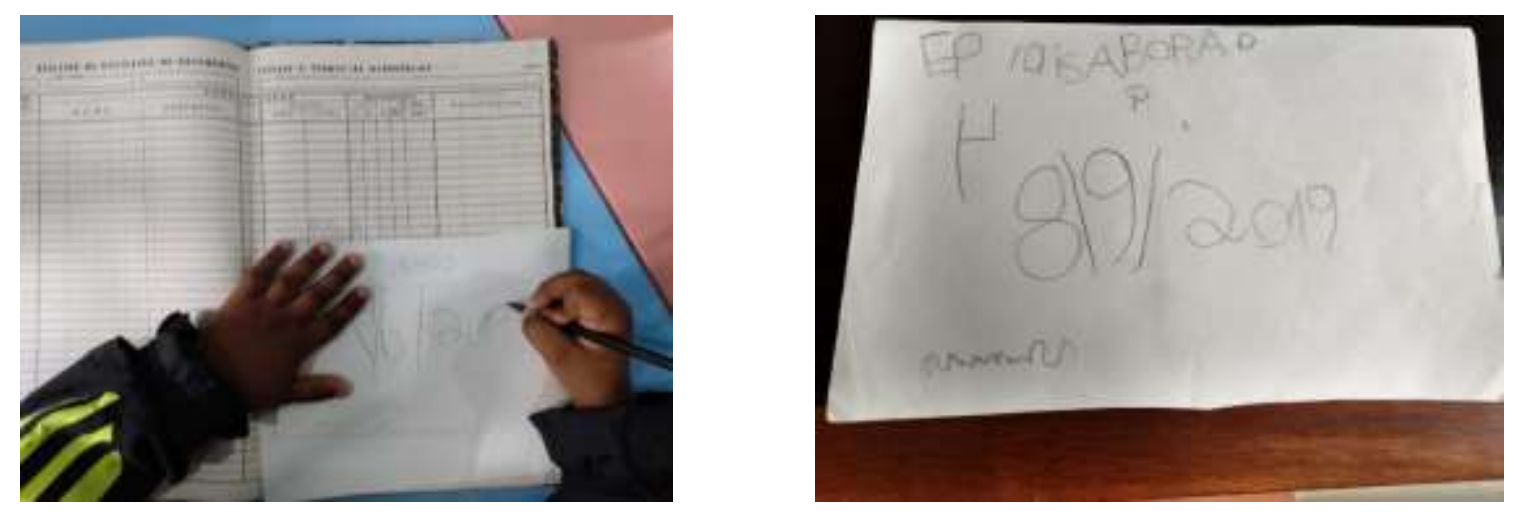

Fonte: Arquivo pessoal.

$\mathrm{Na}$ cena descrita acima, é possível verificar o quanto de conhecimento sobre a leitura e escrita essas crianças já possuem, pois elas a percebem inclusive em uma situação vivida fora da escola e conseguem, através não apenas da oralidade, mas também do registro escrito, comprovar que já percebem o uso social da escrita, enquanto linguagem. Para escrever o nome do "medicamento", $T$. usa letras de nomes dos colegas que estavam sentados à mesma mesa que ele, começados pelas iniciais: P. e I., e escreve também o meu nome, que mesmo estando ali como professora, apenas observava a brincadeira numa cadeira próxima.

Nessa situação, não precisei fazer nenhuma interferência ou orientar às crianças, pois elas demonstraram perceber uma situação escrita e fizeram uso dela com segurança e contexto. Demonstraram, mais uma vez, a importância de explorarem a escrita mesmo que não o façam todo o tempo de forma convencional, como esperam os adultos, mas sim tendo a oportunidade de usar os conhecimentos que já possuem sobre esta área para trazer as situações reais em suas brincadeiras cotidianas.

\section{Considerações Finais}

Uma vez que seja a escola um lugar propício para a exploração da linguagem, é nela também que podem ser oferecidas formas variadas de se conhecer e aprender sobre o seu uso. É, portanto, um desafio da Educação Infantil que as práticas sociais de leitura e escrita presentes em nossa cultura possam ser vivenciadas por meio de experiências.

Na Educação Infantil, as linguagens pelas quais as crianças vão aprendendo a fazer uso para se comunicarem, devem ser vividas, sentidas e ter significado. Não se pode separar o sentir 
do viver, tampouco esperar que o registro escrito desse sentir e viver se distancie da escrita real daquilo que as crianças pretendem comunicar. "Nesse sentido, a Educação Infantil tem o importante papel de possibilitar o acesso à cultura letrada, a partir da vivência e de experiências com diversos suportes e gêneros textuais, em práticas sociais reais em que o uso desses textos se torne necessário.” (FARIA; SALLES, 2012, p. 136)

Assim sendo, a professora da Educação Infantil deve estar mais voltada para essa construção do sentido, da valorização da escrita da criança e do despertar do interesse por mais essa linguagem, não ficando apenas no lugar de quem corrige ou de quem pune e apresenta resultados diferentes do que ele espera. Nessa fase, viver com tranquilidade o processo é o que pode garantir os melhores resultados.

Mas então, qual seria o lugar da escrita na Educação Infantil? Aprende-se a ler e a escrever fazendo cópias? Ordenando ou separando sílabas para depois ler a palavra, o texto? $\mathrm{Ou}$ o texto pode ser muito para crianças pequenas? Em quais momentos, as crianças podem escrever sobre o que pensam, vivem ou desejam? Será que enquanto professores de Educação Infantil podemos propiciar que a escrita das crianças seja vivenciada? Criança também lê e escreve?

Antes de mais nada, é preciso entender que a escrita não é um mero saber escolar e sim uma prática social. Portanto, ela precisa ser compreendida e incorporada pelas crianças através de um trabalho que seja significativamente contextualizado, permeado por textos reais que estimulem a criatividade, criticidade e autoria infantil.

Ou seja, é importante que as crianças possam vivenciar cotidianamente situações que envolvam leitura e escrita e, por conta disso, são levadas a conhecer e fazer uso dessa linguagem de acordo com suas hipóteses e criações desde cedo para que aos poucos possam compreender os seus usos para a vida.

\section{Referências}

AMARAL, Heloísa. Na prática a teoria é outra? In: Revista Na ponta do lápis, Cenpec. Ano III, Nº5, São Paulo, 2007.

BRASIL. Ministério da Educação. Diretrizes Curriculares Nacionais para a Educação Infantil: Ministério da Educação. Brasília: MEC, SEB, DICEI, 2013.

BRASIL. Ministério da Educação e do Desporto. Secretaria de Educação Fundamental. Referencial Curricular Nacional para a educação infantil. Ministério da Educação e do Desporto, Secretaria de Educação Fundamental. Brasília: MEC/SEF, Volume 2: Formação Pessoal e Social, 1998.

CORSINO, Patrícia (org.). Educação Infantil: cotidiano e políticas. Campinas: SP: Autores associados, 2009. 
FARIA, Vitória Líbia Barreto de, SALLES, Fátima. Currículo na educação infantil: diálogo com os demais elementos da proposta pedagógica. São Paulo: Ática, 2012.

FERREIRO, Emília. Com todas as letras. / Trad. de Maria Zilda da Cunha Lopes; Retradução e cotejo de textos Sandra Trabucco Valenzuela- $8^{\mathrm{a}}$ ed. São Paulo: Cortez, 2000.

FREIRE, Paulo. A importância do ato de ler: em três artigos que se completam. São Paulo: Autores associados: Cortez, 1989.

GUEDES, Adrianne O., BARREIROS, Tereza Cristina. Cartas sobre leitura e escrita na PréEscola ou a formação de narradores: uma paixão nas entrelinhas. In: Infância e Educação Infantil. São Paulo: Papirus 2011.

LARROSA, Jorge. Notas sobre a experiência e o saber de experiência. In: Revista Brasileira de Educação. Trad. João Wanderley Geraldi, nº 19, 2002.

LERNER, Delia. É possível ler na escola? In. Ler e escrever na escola. O real, o possível e o necessário. Porto Alegre, Artmed, 2002.

MORAIS, Artur Gomes de. Práticas de Ensino do SEA: princípios gerais e atividades voltadas a compreender as propriedades do sistema. Reflexões sobre o ensino do Sistema de Escrita Alfabética. In. MORAIS, Artur Gomes de. Sistema de Escrita Alfabética. São Paulo: Editora Melhoramentos, 2012.

\footnotetext{
${ }^{\text {i }}$ A Pré-escola compreende crianças com faixa etária entre 4 e 5 anos, porém, na Pré-Escola II, algumas crianças já têm 6 anos completos.

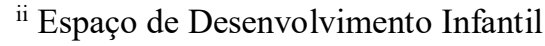

iii Uma vez que, a autora do texto é uma professora, mulher, gênero feminino e que no Brasil, a profissão de professora na Educação Básica é prioritariamente ocupada por mulheres, escolho utilizar o substantivo sempre no feminino ao longo do texto.

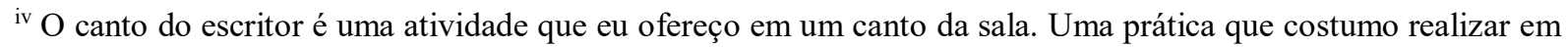
minhas turmas deixando que escrevam de forma livre e como concebem. Pode ser em cima de um tecido forrando o chão, ou numa mesa. Algumas vezes ele é oferecido para o grupo por mim e outras vezes solicitado pelas crianças. Nesse canto, são oferecidos cadernos, bloquinhos, papéis diversos, revistas, guias médicos, lápis, borrachas e canetinhas.

${ }^{v}$ Os nomes das crianças e familiares que aparecem no texto, serão indicados pelas iniciais para preservar suas identidades.

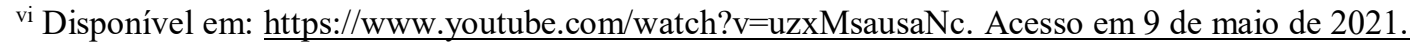

